\title{
A Research on Cognitive Metonymy Models of News Headlines from
} ft.com

\author{
Chunyan Mai \\ Correspondence: Chunyan Mai, Yancheng Teachers’ University, China.
}

\author{
Received: August 5, 2019 \\ Accepted: September 15, 2019 \\ Online Published: September 18, 2019 \\ doi:10.5430/elr.v8n4p1 \\ URL: https://doi.org/10.5430/elr.v8n4p1
}

\begin{abstract}
News as a literary form adopted by public media, has been playing an important role in reporting international events. Due to the fast pace of life in today's society, readers usually grasp the major events by just reading the headlines. While the headline as the "eye" of a piece of news, enables the readers to catch the key and hot point at the first time by means of its terse and concise words. With the rise of cognitive linguistics, metonymy is regarded not only as a rhetorical device, but also as a way of thinking the objective world. What's more, metonymy also plays an important role in the news headline discourse organization. Therefore, based on the cognitive metonymy theory, this research makes the case studies of the news headlines which contain metonymy in order to answer the two questions: (1) Among the different kinds of cognitive metonymy models, which one is used the most frequently in news headlines? (2) Are the natures and values of news headlines related to the choice of these cognitive metonymy models?
\end{abstract}

Keywords: cognitive metonymy, news headlines, idealized cognitive model

\section{Introduction}

News has been playing an increasingly crucial role in the social life, which enables readers from all over the world to know the latest information about international development. The new information age witnesses the dramatic usage of the Internet, among which, ft.com provides readers with the latest information and enables them to leap over the narrow personal boundary to embrace the broad social life.

However, headlines as the soul of news, not only play the role of catching the readers' attention, but more importantly, summarize the key information of news. More often than not, the readers usually figure out whether this piece of news is the one that they want to get some information from the news headlines, especially in this fast-paced society. Due to the importance of its language features and unique functions of the news headlines, many aspects of them have been explored, such as philosophical, political, psychological and cultural aspects, etc. In comparison, these researches lack in thoroughness in terms of research scope and in sharp discernment in view of analytic perspective, so more efforts are required at studies beyond these surface linguistic features. With the development of cognitive linguistics, which is an approach to language that is based on people's experience of the world and the way people perceive and conceptualize it, the viewpoint that human cognitive mechanism determines language structure and language behavior becomes a hot issue. This view triggers the study of cognitive concepts used in various kinds of works, with no exception to news headlines, in which the use of metonymy lends evidence to the fact that metonymy is more than a linguistic feature but a cognitive way of thinking.

This research adopts quantitative and qualitative analysis with a total of 223 pieces of news headlines collected from ft.com from April, 2018 to April, 2019, because ft.com is the only website of Financial Times aimed to provide the latest information in terms of English business, marketing, finance and so on with rich and colorful contents with over 3.9 million online readers every month. Metonymy is a cognitive and linguistic process through which people use one thing to refer to another (Jeannette Littlemore, 2015: 1). Generally speaking, metonymy can make the language simple, powerful and humorous. Therefore, based on the cognitive metonymy theory, this study attempts to answer the following questions, (1) Among the different kinds of cognitive metonymy models, which one is used the most frequently in news headlines? (2) Are the natures and values of news headlines related to the choice of these cognitive metonymy models?

This thesis consists of five chapters. Chapter one is a brief introduction, including the background, purpose, methods, and overall structure of the thesis. Chapter two is the literature review of the previous studies on news headlines and the concept of cognitive metonymy. Furthermore, at the end of this chapter, the working mechanism of metonymy 
will be focused on, containing idealized cognitive model, cognitive reference point, mapping, and highlighting. Chapter three is about the research methodology. It revolves around the data collection and research procedures. Chapter four is the core of this thesis which concerns about the analysis of cognitive metonymy models employed in news headlines. It starts with a general introduction to the natures and values of the news headlines, then, the cognitive metonymy models used in news headlines are to be analyzed. Chapter five is a conclusion that recapitulates the results and the significance of the present research, points out its limitations and shows directions for further study.

\section{Literature Review}

This chapter mainly reviews the previous studies on news headlines and the concept of cognitive metonymy. Since 1980s, enthusiasm for news studies has shown itself in plentiful researches of many scholars. It is well known that a piece of news normally consists of three parts, the headline, the leading part and the body, in which news headline is the "eye" or the "core" of the news. Generally speaking, news headlines are often printed in large type, but the primary reason is that they help readers get the message they are interested in at a quick glance, therefore, its language is most important.

\subsection{Previous Studies of News Headlines}

At all times, the research of news headlines has never slipped out of scholars' attention, because researchers have done plenty of researches about news headlines, due to its important roles. Therefore, various methods are applied to analyze the linguistic features in this special field. To name a few, O'Donnell and Todd make a comparative study of the linguistic features in The Guardian and The Daily Mirror, while Carter studies the lexical and syntactic features in News, Gender and Power (Carter, 1998: 36-44), and not long ago, Alice Deignanl (Deignanl, 2001: 187) suggests that a corpus or several corpora for news headlines should be built to promote the study in news language, especially news headlines.

Because of the increasingly important position English news holds in society, many studies have also been carried out on news headlines in China, such as Heading Grammar written by Shichao Yin who studies news headlines from three aspects of syntax, semantics and pragmatics (Shichao Yin, 2005: 68-84). Lizhao Chen makes a comparative study between grammar and rhetoric on English news headlines (Lizhao Chen, 2002). Fang Tang makes an analysis about news headlines from non-category, which provides a new perspective for the study of news headlines to help readers better understand the news headlines in expression (Fang Tang, 2012). Leifu Zhang collected many sports news headlines and combined the cognitive metaphor theory to analyze the reason making English sports news headlines so special (Leifu Zhang, 2009).

However, with the progress of cognitive linguistics, studies from the inner element view on the subject are clearly in great need. Therefore, the present research attempts to study news headline features from this inner cognitive perspective, together with insights from outer factors, aiming to offer a better understanding of news language.

\subsection{Cognitive Metonymy Overview}

Cognitive metonymy theory indicates clearly people's fundamental cognitive pattern and explains basic cognitive concepts that are indispensable in understanding news language in a cognitive view. Therefore, before this research steps into the cognitive analysis of news headline language, cognitive metonymy theory should be introduced in advance.

\subsubsection{Cognitive Understanding of Metonymy}

Metonymy can be dated back to ancient Greek, which refers to "change of name". However, in Metaphors We Live $B y$, Lakoff and Johnson point out that besides metaphor, there is a related conceptual mechanism that is also central to human thought and language---metonymy, (Lakoff \& Johnson, 1980: 4) which was traditionally regarded as a purely linguistic device. In recent years, a considerable amount of studies have been devoted to metonymy. In fact, some scholars even suggest that metonymy may be more fundamental to conceptual organization than metaphor, and some of them have claimed that metaphor has a metonymic basis. Therefore, metonymy is a phenomenon of conception, a process of cognition, which often involves using a simple or concrete concept to refer to something that is more complex or more abstract, or even sensitive.

With many extensive researches taken, it has been found that the essence of language is metonymy. What's more, cognitive linguists have given an agreement on the definition of cognitive metonymy that metonymy is a cognitive phenomenon associating much with people's ordinary thinking and the use of metonymy in a language is a feedback of its conceptual status. 
At the very beginning, most cognitive linguists consider that metonymy is just conceptualized by the proximity of things. Later on, Lakoff and Turner (Lakoff \& Turner, 1989: 103) treat metonymy as a mapping between two conceptual entities in one cognitive domain, which involves a "stand-for" relationship and partly has a referential function. But this definition is too narrow, because metonymy is only regarded as a referential phenomenon in the definition. What's more, metonymy is limited in the physical world since it's confined to those spatial-temporal contiguity. Therefore, this definition is not fully reflected the conceptual nature of metonymy.

Based on the conception of Lakoff's idealized cognitive model, Radden and Kovecses make a further investigation on a comprehensive definition of metonymy in their work "Towards a Theory of Metonymy". They define metonymy as "a cognitive process in which one conceptual entity, the vehicle, provides mental access to another entity, the target, within the same idealized cognitive model" (Radden \& Kovecses, 1999: 21). This definition provides three assumptions about metonymy which is very different from the traditional views. "First, metonymy is a conceptual phenomenon; second, it is a cognitive process; third, it operates within the same idealized cognitive model" (Radden \& Kovecses, 1999: 22). So far, it is the most widespread cognitive definition of metonymy. These three important assumptions can be explained in detail one by one.

First, metonymy is a conceptual phenomenon, which indicates metonymy now is not only limited as a rhetorical device, but also supposed to be a conceptual phenomenon. Metonymy offers people a basic mode of thinking based on human experience, which is used to conceptualize human's thoughts and actions. For example, Lakoff and Johnson, used the famous example that "she's just a pretty face" to illustrate the general conceptual nature of metonymy. In this case, the THE FACE is used to refer to THE PERSON, because face is the most salient part, therefore conceptual metonymy is an important part of basic way of thinking about people.

Second, metonymy is a cognitive process. Look at the example "She is just a pretty face" again. This sentence means "She is just a pretty person", because the face here refers to a substitute expression for person. However, it doesn't mean she is pretty in every aspect, on the contrary, it implies that she just has a pretty face, perhaps, she is not very competent. Generally speaking, people usually perceive the person in terms of other's face and act on those perceptions to get their basic information about what the person is like. Metonymy connects one entity with another, and then to form a new, complex meaning.

Third, metonymy operates within one idealized cognitive model. It is assumed that metonymy phenomena is an idealized cognitive model(ICM), which means metonymic contiguity within the framework of idealized cognitive Lakoff and Johnson (Lakoff \& Johnson, 1980: 35) point out that contiguity is located at the conceptual level occasionally related to an expression with regarding to the whole range of conceptual associations. A domain or a domain matrix is used by Croft to deal with contiguity relations of encyclopedic knowledge representation. Blank, Panther and Thornburg describe the conceptual contiguity by using the notion of frame and scenario respectively.

\subsubsection{Three Models of Cognitive Metonymy}

As a cognitive phenomenon, metonymy has different and diverse forms in language. Therefore, in both traditional and cognitive studies, the classification of the metonymy is also an important study. There is a variety of classifications about metonymy in academic circle, and this study will focus on the most typical classification, namely Panther and Thornburg's (Panther \& Thornburg, 1998: 755-769) classification which categorizes metonymy according to what it is used for.

Panther and Thornburg (Panther \& Thornburg, 1998: 755-769) offer a fine-gained classification that the metonymy is divided into three categories: referential metonymy, predicational metonymy and illocutionary metonymy.

Referential metonymy is the most prototypical one, because this type of metonymy is a referential shift phenomenon where one entity is related to another.

Example1: Japan refuses to give greater access to US farmers (2019.4.29)

Example2: China increases gold holding for fourth straight month in March (2019.4.9)

In example 1, Japan the name of the country is used to stand for Japanese government. This is a kind of referential shift phenomenon, because Japan and Japanese government have a close relationship. In example 2, China is used to refer to the leader of the Chinese bank, which is also a typical instance of referential metonymy.

Predicational metonymies mostly involve relationships between events. Here's example 3 and 4:

Example3: A 1tndollars global trade war could yet come to pass (2018.7.4)

Example4: Tariffs could lop 0.5 points off global growth, IMF warns (2018.7.17) 
In example 3, "could yet come to pass" metonymically evokes the fact that "global trade war has been passed". In example 4, "could lop" metonymically stands for the fact that "tariffs did lop the global growth". Panther and Thornburg (Panther \& Thornburg 1998: 755-769) point out that in theses predicational metonymies, a potential event expressed through a form of modality is metonymically linked to its occurrence in reality.

Illocutionary metonymy involves pragmatic inference, which relies on scenario-based relationships. According to Panther and Thornburg, the "literal" meaning of a metonymy is always relevant to the interpretation of a metonymic expression, which is not the case that metonymy simply involves the substitution of one word for another. Here is example 5: Theresa May vows to fight for her Brexit deal (2018.11.16).

In this case, the word "vow" would involve a precondition that Theresa May has made up her mind to fight for her Brexit deal and she believed she had the ability to do that. Another case in example 6: Buffet offers rare admission of failure in saying Berkshire overpaid for Kraft (2019.2.26) . In example 6, "admission of failure in saying" indicates the whole event of "the failure of the investment in the food company of Kraft". These two examples show that metonymy analysis does not throw away pragmatic analysis, on the contrary, pragmatic clear meaning and hidden meaning is derived in large part depending on metonymy.

\subsection{Working Mechanisms of Metonymy}

\subsubsection{Idealized Cognitive Models}

From the definition of cognitive metonymy, it works within a single idealized cognitive model (ICM). Human's knowledge is built with the world in terms of idealized cognitive models (ICMs). Thus their understanding and operation about metonymy is based on the notion of ICM. Lakoff (Lakoff, 1987: 67) firstly defines idealized cognitive model in the book Women, Fire and Dangerous Things. ICMs offer the basic patterns to structure human's minds and knowledge. For example, Fed weighs significant uncertainties over global (2019.4.11). In this example, Fed is used to stand for the decision makers, while the decision makers of Fed and the organization of Fed both belong to the same category, therefore, they are in one ICM.

In short, metonymy works within a single idealized cognitive model (ICM), because ICM does not exist in the real world but idealized. Everything in the ICM mode is a conceptual entity, and metonymy is in accord with the entity. In order to understand and generate metonymy, ICMs provide a good background. In other word, to learn the idealized cognitive model theory is to understand the essence of metonymy.

\subsubsection{Cognitive Reference Point}

Metonymy's process includes one conceptual entity access to another conceptual entity, which is a cognitive one. Langacher (Langacher, 2000: 69) argues that metonymy is a cognitive reference-point expression in which the core of a concept is used to highlight the less prominent projects. It is sometimes linked to the attention scope, which is the boundary between the attention and the object. Metonymy concludes the relationship between the reference point and the scope. The ingredient in discourse is highlighted by the reference point, and the reference point is established as a result which comes to a context. For instance, Talks to avoid second US shutdown are deadlocked (2019.2.11), here "talks" is used as the most salient part to stand for the "meeting" to evoke readers' knowledge.

This reference point phenomenon is a cognitive mechanism which is basically and pervasively in human's everyday life, and sometimes they are just unaware of it. It has been regarding as a cognitive strategy which is used to conceptualize the world.

\subsubsection{Mapping}

There is a narrow definition of mapping "the projection or superimposition of one structure onto another, so that the projected structure imposes (some of) its internal elements, traits and properties onto their counterparts in the other" (Barcelona, 2000: 25). Mapping can be divided into three types that are projection mapping, pragmatic mapping and schema mapping. The essence of projection metonymy is "stand for". In the pragmatic mapping, two related domains map on pragmatic functions. For example, patients are related to the disease being treated. In schema mappings, the contextual situations can be constructed by a general schema. Barcelona believes that it is through conceptual domain mapping that the schemata or structure of the source domain can be projected to the target domain within an ICM and the source serves as mental access to the target.

\subsubsection{Highlighting}

In recent years, more and more cognitive linguists believe that metonymy is a process of highlighting or activation. Croft (Croft, 2004: 46) considers the conceptual effect of metonymy as domain highlighting. His metonymy contains "domain highlighting". In addition, as the highlighting of specific domains in a domain matrix, a domain is very 
important in most metonymies and some related lexical ambiguities. Only in metonymy, can domain highlighting be known as the mental activation of a certain (sub) domain, the target, with another (sub) domain, the vehicle. This intradomain activation is crucial to metonymy.

For example, White House suspends press pass of CNN reporter (2018.11.9)

This is a typical example for metonymy. In this example, the "White House" is the vehicle which refers to the target American government, while White House is a part of American government.

Recently, analyzing news headlines from the perspective of cognitive linguistics has become more and more popular in China too. Such as, Miaomiao Jiang wrote an article called A Study of Metonymy in Advertisements, in which the author tried to make a study on the working mechanism of advertising from the perspective of cognitive metonymy, and explored its functions in advertising language (Miaomiao Jiang, 2012). Wei Wang focused on the contrastive study of metonymy from the cognitive perspective, with Chinese and English political news headlines to try to make a comparative study of English and Chinese languages (Wei Wang, 2014). However, there is not much research about English news headlines from the perspective of cognitive metonymy models in China.

\section{Research Methodology}

As is shown in the previous chapter, few researchers build a corpus to study the models of metonymy used in the news headlines. Therefore, this research uses the 223 pieces of news headlines collected from ft.com as a corpus which is based on the cognitive metonymy theory, and attempts to answer the following questions:

(1) Among the different kinds of cognitive metonymy models, which one is used the most frequently in news headlines?

(2) Are the natures and values of news headlines related to the choice of these cognitive metonymy models?

In order to answer the above questions, this chapter describes the methodology employed in this study, including data collection and research procedures.

\subsection{Data Collection}

A total of 223 pieces of news headlines are collected from ft.com from April 29, 2018 to April 29, 2019, based on three reasons. First, because ft.com is the only website of Financial Times aimed to provide the latest information in terms of English business, marketing, finance and so on with rich and colorful contents. Second, its main website, ft.com, has more than 3.9 million online readers per month, which shows its position as characteristic example in the field of world-renowned international financial media. Third, 223 pieces of news headlines from April, 2018 to April, 2019 cover a wide range in contents and in time, which is more objective.

\subsection{Research Procedures}

In order to find out the cognitive metonymy models underlying news headline language, a qualitative study together with a quantitative one is carried out. Firstly, the research adopts a qualitative approach in analyzing the cognitive metonymy models used in news headlines, aiming to reveal the cognitive process of forming news headline language. Secondly, a quantitative research will be conducted to find out the cognitive metonymy models often used in news headlines, especially by counting up the frequencies of each cognitive model employed by those samples. In this way, the cognitive metonymy models often used in producing news headline language are obtained. Then in the following chapter, the research will explain in detail how news natures and values are related to these cognitive metonymy models and specifically how they affect the choice of these models in news headlines.

\section{Analysis of Cognitive Metonymy in News Headline}

News headlines always use metonymy to convey information more clearly. Consider the following examples:

(1) Trade talk hopes keep Wall Street on upward track. (2019.1.8)

(2) Democrats vow to keep up Trump-Russia investigate. (2019.3.25)

(3) US-China trade talks could stretch for 'months'-- Kudlow (2019.3.29)

In example (1) the word "Wall Street" refers to the stock market of the USA, because it is well known that Wall Street is the economic center of the USA. The use of this typical case of referential metonymy makes the headline simple and easy to understand. When this headline is read, ICM will be activated to infer the content of the news, and then readers will be eager to read the whole news. While in example (2) the phrase "vow to keep up" indicates that the whole process of investigating the Trump-Russia events. With the help of this illocutionary metonymy, the headline will stimulate the readers' interest to read the news in detail. Example (3) uses "could stretch for "months" to express the 
fact that the US-China trade talks have the potential possibility to last for months. Because of this predicational metonymy, most readers will be eager to read the details of the news to find the hidden reasons. Although these three kinds of metonymy models all often appear in the news headlines, they are used at different frequencies.

\subsection{Data Analysis}

The following table shows the information of 223 pieces of news headlines from ft.com from April, 2018 to April, 2019 used as the samples in the research.

Table 1. Headline Sample Information

\begin{tabular}{l|c|c}
\hline \multicolumn{1}{c|}{ Metonymy models } & Frequency & Percent \\
\hline Referential metonymy & 191 & $95 \%$ \\
\hline Predicational metonymy & 2 & $1 \%$ \\
\hline Illocutionary metonymy. & 9 & $4 \%$
\end{tabular}

From the above table it can be concluded that as a kind of common cognitive mechanism, metonymy is also widely used in the news headlines. Among the 223 pieces of news headlines, the metonymy models are used in 202 pieces, especially the referential metonymy, which to some degree represents news language because news headline language is typical of news language. Thus this research can offer insights into news headline language.

The main function of news headlines is to attract readers because readers usually decide whether to read the news or not in a very short time. The referential metonymy is a referential shift phenomenon where one entity is related to another, which helps readers understand the headlines better quickly and also meets the requirement of the news headlines to attract readers. However, predicational metonymies mostly involve relationships between events and illocutionary metonymy involves pragmatic inference, which relies on scenario-based relationships. Therefore, these two metonymy models are not as concrete as the referential metonymy.

Among the main referential metonymy models, a detailed description of qualitative and quantitative results is also presented, in addressing to the second question---Are the natures and values of news headlines related to the choice of these cognitive metonymy models?

Table 2. Qualitative and quantitative results

\begin{tabular}{l|c|c}
\hline \multicolumn{1}{c|}{ Main referential metonymy models } & Frequency & Percent \\
\hline Name of the country represents the leader & 49 & $26 \%$ \\
\hline Name of the company represents the leader & 49 & $26 \%$ \\
\hline Districts represents others & 26 & $14 \%$ \\
\hline Acronym represents the organization leader & 27 & $14 \%$ \\
\hline Acronym represents the government & 40 & $20 \%$ \\
\hline
\end{tabular}

Among the 191 pieces of news headlines used referential metonymy, 49 pieces use the name of the country to represent the leaders, which takes up $26 \%$, such as,

North Korea calls Madrid embassy raid a 'grave terrorist attack' (2019.4.1)

In the above headline the word "North Korea" is in fact used to mean the leader of North Korea's government.

Another 49 pieces use the name of the company to represent the policymakers of the company which also accounts for $26 \%$. For example,

Apple spends hundreds of millions on Arcade video game service (2019.4.15)

In the above headline, the name of the company "Apple" is actually used to refer to the leader of the company.

These two types of metonym employ the principle of prominence supported by part-whole schema with the name of the country or the name of the company as salient parts replacing other members of unitary conceptual domains and standing for whole conceptual systems.

The 26 pieces of news headlines up to $14 \%$ use the name of the districts to represent other things. For example,

Heady returns for Burgundy investors as index climbs a third (2019.1.21)

Here "Burgundy" is used to represent the wine produced in this district, which can stimulate people's ICM easily to infer the content of the news. 
However, acronyms can be regarded as employing metonymy with schema as their cognitive model. In view of the metonymy principle of prominence that says salient aspects of a conceptual structure are easily perceived and memorized. Therefore, among the 191 pieces of the news headlines, 27 pieces use acronyms to represent the organization leaders, which accounts for $14 \%$, while 40 pieces use acronyms to represent the governments which takes up $20 \%$. For example,

Lira comes under new pressure after US warns of new sanctions (2018.8.17)

Here the acronym "US" is used to refer to the government of the United States, not the country itself in fact. Another example,

IMF warns world to cut 164tn dollars debt pile (2018.4.19)

In this headline the acronym "IMF" to the decision makers of the International Monetary Fund.

The language of the news headlines requires simplicity in form, width in application scope and conceptual meaning range, and frequency in usage. The salient position of the referential metonymy just meets the requirement of the news headline language. In other words, news headlines as the factor that affects choice of cognitive metonymy models.

In News Commentary Written Series (Chunhua Ye, 2000: 5), headline is defined as "news headline is the topic of news, which highly summarizes the basic content of the news (facts and ideas), in order to attract the audience, impact on the audience, and help the audience read news, understand the news, therefore, news headline is called the newspaper's eyes." From the definition of the news headline, it can be concluded that there are some features of news headlines. First, news headlines are relatively brief; second, news headlines are succinct summaries; third, news headlines are easy to read and attract readers.

\subsection{Functions of Metonymy in News Headlines}

The functions of metonymy are often related to the human communication principles, such as the principle of economy, that is, to use the least effort to get the most meanings and the principle of optimal relevance. More often than not, speakers don't provide all the information they want to convey. Instead, they use the most relevant, salient, and easy-to-perceive information to represent what they want to convey. Therefore, metonymy as a significant and fundamental cognitive tool is used widely and it also plays a key role in the news headlines. In the course of analyzing and understanding of the news headlines, the functions of metonymy shouldn't be neglected because experiential grounding makes the mapping process acceptable and easily perceived by news readers. According to the collection of news headlines, a further study on the functions of metonymy used in news headlines can get the following conclusions.

First, metonymy helps readers arouse their perception. As is known to all, good news headlines should be eye-catching rather than being full of boring elements. News headlines are some kind of communication method with specific aims. Hence the language of the news headlines should meet readers' expectation. However, the editors can't talk to the readers face to face, so what the editors can do is to use metonymy in news headlines to bridge the information gap between the readers and what news headlines express. By using metonymy in news headlines, it is easy to make readers understand more abstract and less accessible ideas.

Second, metonymy helps stretch readers' imagination. As is well known, the Idealized Cognitive Model is the basis of understanding and operation of metonymy. Many conceptual relations are involved in the ICM frame. Among the conceptual relations, there is much information unknown clearly and it should be bridged between these information gaps. In the process of understanding the metonymy expressions in news headlines' language, the information gaps will be filled unconsciously. The more information gaps there are, the more room for imagination there will be. Thus, metonymy can greatly mobilize and activate the imagination of readers. That's why a lot of good news headlines are forever tasty and imaginative.

Third, metonymy helps readers build a more vivid image. Take "US official paints gloomy pictures for soybean farmers" (2019.2.22) as an example, in which "gloomy pictures" is used vividly to activate the readers' imagination to have a clear image about the future life of the soybean farmers in their mind, which is that they will have a difficult life.

Last, metonymy helps catch the attention of readers. Readers are always curious about new things and metonymy as a cognitive thinking mode provides a novel approach for them to accept new things. It means the using of metonymy in news headlines can arouse readers' curiosity. In this way, can it achieve the communicative purpose of news headlines. 


\section{Conclusion}

In this information explosion era, news occupies an important part. Metonymy as a part of cognitive linguistics, it draws readers' attention to focus on the more significant aspects of the objects which readers are interested in. Therefore, metonymy is used widely in news headlines, from the perspective of using the cognitive metonymy to attract reader, to making headlines meaningful. The advantage of newspaper is time-sensitive, news headlines are the eyes of news, and readers can save time by just reading the news headlines because metonymy is a cognitive process of thinking. In essence, it is conceptual. Among the 223 pieces of news headlines, the metonymy models are used in 202 pieces, especially the referential metonymy, which to some degree represents news language because news headline language is typical of news language.

In addition, it is also found that metonymy provides the simplest and most direct way to convey what the sender wants to say. It helps arouse readers' perception, extend their imagination and help them create a more vivid image. However, because the limited time and experience, there is still a lot to research further. For example, this research uses the news headlines collected from ft.com from April 29, 2018 to April 29, 2019. Whether other headlines satisfy the conclusion is still unknown.

\section{Funding Project}

One of the phased achievements of the project of Humanities and Social Sciences of Yancheng Teachers' University, "Research on Metonymy Mechanism in Cognitive Pragmatics" (Project No. 72031761012D).

\section{References}

Alice, D. (2001). Collins Cobuild English Guides 7: Metaphor. Hong Kong: the Commercial Press.

Antonio, B. (2000). Metaphor and Metonymy at the Crossroads. Berlin: Moulton de Gruyter.

Chen, L. Z. (2002). A comparison of grammatical features between Chinese and English news headlines. Papers of the 2002 Conference of Fujian Foreign Language Society, 2002(4).

Cynthia, C. (1998). News, Gender and Power. London: Routledge.

George, L. (1987). Women, fire, and dangerous things: what categories reveal about the mind. Chicago: University of Chicago Press. https://doi.org/10.7208/chicago/9780226471013.001.0001

George, L., \& Johnson, M. (1980). Metaphors we live by. Chicago: The University of Chicago Press. https://doi.org/10.7208/chicago/9780226470986.001.0001

George, L., \& Johnson, M. (1980). Metaphors we live by. Chicago: The University of Chicago Press.

George, L., \& Turner, M. (1989). More than cool reason: A field guide to poetic metaphor. Chicago: University of Chicago Press.

Günter, R., \& Kövecses, Z. (1999). Towards a Theory of Metonymy. Amsterdam: John Benjamins. https://doi.org/10.1075/hcp.4.03rad

Jiang, M. M. (2012). Metonymic Analysis of Advertising Language. Journal of Xihua University, 2012(5).

Klaus-Uwe, P., \& Thornburg, L. (1998). A cognitive approach to inferencing in conversation. Journal of Pragmatics, 30(6). https://doi.org/10.1016/S0378-2166(98)00028-9

Littlemore, J. (2015). Metonymy: Hidden Shortcuts in Language, Thought and Communication. London: Cambridge University Press.

Ronald, L. (2000). Grammar and Conceptualization. Berlin: Moulton de Gruyter.

Tang, F. (2012). Decategorization of Chinese News Titles. Journal of Guangxi Normal University, 2012(7).

Wang, W. (2014). A Contrastive Cognitive Analysis of Metonymy in Chinese and English Political News Titles. Journal of Xi'an Foreign Studies University, 2014(3).

William, C., \& Cruse, A. (2004). Cognitive Linguistics. Cambridge: Cambridge University Press. https://doi.org/10.1017/CBO9780511803864

Ye, C. H. (2000). News Acquisition, Writing and Reviewing. Shanghai: News Acquisition, Editing and Reviewing Fudan University Press.

Yin, S. C. (2005). Title Grammar. Beijing: Commercial Press.

Zhang, L. F. (2009). A Study of War Metaphors in Chinese and English Sports News. News Knowledge, 2009(8). 